\title{
Computational modeling of battery thermal energy management system using phase change materials
}

\author{
Pusapati Laxmi Narasimha Raju(D), Chalumuru Manas, and Harish Rajan* (D) \\ School of Mechanical Engineering, Vellore Institute of Technology, Chennai 600127, Tamil Nadu, India
}

Received: 10 January 2021 / Accepted: 27 October 2021

\begin{abstract}
Similar to an IC (Internal combustion) engine which requires cooling to operate at optimum temperature for better efficiency; electric vehicles do require a similar system. There are various methods used in the current market for thermal management of batteries, of these our paper focuses on phase change materials (PCM). This cooling strategy can store an enormous amount of heat produced inside a battery because of its high latent heat capability. A 3D model of the battery using the multi-scale multi-dimension model (MSMD) for battery simulation and Solidification/melting models were used to showcase the melting of PCM due to the heat generated from a cell. ANSYS fluent was used to carry out the simulations. These computations are carried out at different C-rate to find the time taken for a battery to discharge and to find the impact of C-rate on PCM performance. Besides, temperature data for the cell was recorded before and after PCM was involved to compare the temperature difference between various PCM's.
\end{abstract}

Keywords: Phase change / battery cooling / N-Octadecane / liquid fraction / cell potential

\section{Introduction}

The battery framework is the essential energy for electric vehicle (EV's) to power the motors, it is necessary to have a rugged and long-lasting design. While designing a battery system factors like performance, safety, and life cycle play a key role. In order to improve such crucial factors battery thermal management needs to be taken care as it helps the battery from undergoing an extensive heat load causing damage to its life and performance. Phase change materials have wide applications in thermal energy sector, as they can help reduce and transfer heat when necessary. During the charging and discharging operation of any battery, large amounts of heat are generated and a temperature rise can also be noted. This rise in temperature if it exceeds the optimum range affects battery life, performance, and safety. So, it is imperative to use a battery thermal management system (BTMS) to sustain the surface temperature of cells for providing a better output. Usually, the optimum temperature range for battery operation is between $20^{\circ} \mathrm{C}$ and $50^{\circ} \mathrm{C}$. PCM is a latent heat storage element which is very well capable of releasing and storing heat, which also involves phase transition. When the temperature of a battery exceeds the melting temperature of a PCM, the heat generated will be absorbed by the PCM

\footnotetext{
* e-mail: harish.r@vit.ac.in
}

and stored as latent heat further limiting the increase in battery temperature.

In contemporary, various BTMS are in practice which involves air cooling, liquid cooling, and PCM cooling. Kim [1] based on review of battery thermal management system in EV's where air and liquid cooling are traditionally being used from the past for thermal management. These systems use equipment that requires complicated design and installation methods for their circulation and water can only operate up to a certain temperature which limits its capability to operate beyond range. To substitute these traditional methods, we require systems that are less complex, easy to install, and cost-effective. Phase change materials (PCM) seem to be a better alternative for these traditional methods, with the ability to work as an efficient thermal management system. Talluri [2] a numerical and computational analysis on phase change material in a 6 - Kw lithium battery module was investigated, which provided relatively better results.

Latent heat storage relies on the heat absorption or release process when the material encounters a phase change process from solid to liquid or liquid to solid. So, PCM's are latent heat storage materials, where exceeding the melting temperature requires energy for the phase transition process. When these PCM's are used in BTMS, they absorb the heat generated from the battery. As the temperature exceeds the melting point, phase transition process begins controlling the battery temperature. As reviewed in Qureshi [3], Mills [4], Ibrahim [5], they have enhanced thermal conductivity of PCM which 


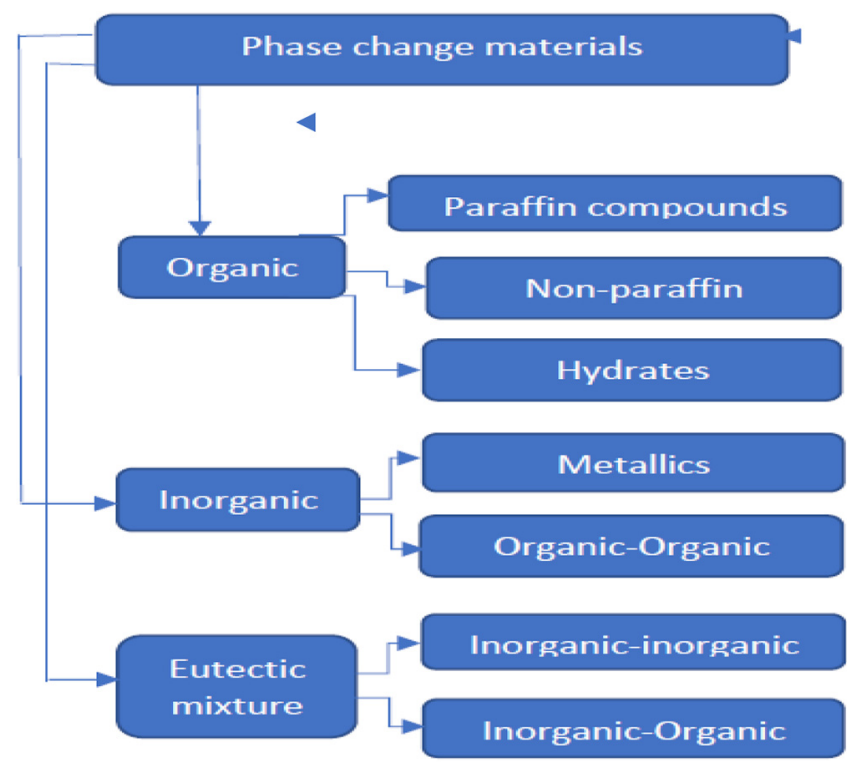

Fig. 1. Classification of phase change materials.

provides an efficient cooling system when compared to traditional systems. Furthermore Fathabadi [6], Ling [7], like various other researchers have contributed to developing an efficient PCM for thermal management involving microencapsulated PCM, composite PCM, porous materials, etc. Zhao [8] has performed simulation combining liquid and composite phase change material to enhance the performance of BTMS. A wide variety of phase change materials are available in the market with varying operating temperatures [9]. Figure 1 describes the classification of PCM's. Of these described elements paraffin are widely recognized and utilized latent heat storage materials, because of their large temperature limits, safe, reliable, and non-corrosive properties. Based on experiments performed by Rao [10], enhancing the thermal conductivity will enhance heat transfer rate from cell to PCM, which allows it to absorb and release heat in lesser time. In addition, experiments performed by Huang [11], Zhanga and Pradeep [12,13] indicates composite phase change materials perform in a better way due to their enhancement in thermal properties which are suitable for most working conditions.

In this paper, we have considered a PCM material wrapped around a battery with 3-cells, assuming similar properties could be illustrated for a battery module. As PCM's have higher latent heat storage capability, Rao et al. [10], it made us curious to investigate about its operation. The objective of this work is to design and analyze a PCM with larger surface area to facilitate better heat transfer and 3-cells were considered over 2-cell to evaluate the surface temperature of cell in contact with PCM experiencing constant heat supply on both their faces. Initial CAD design was created in SOLID WORKS and simulations were conducted in ANSYS FLUENT 2020 using MSMD battery model. We have considered 4 different phase change materials methyl palmitates [14], N-eicosane [15], OM-35 [16], N-octadecane [17], which have different operating conditions, that suit varying weather conditions.
Of these materials, methyl palmitate has shown better results in terms of controlling the surface temperature of the cell at various discharge rates $(1 \mathrm{C}, 1.5 \mathrm{C}, 2 \mathrm{C}, 3 \mathrm{C})$. But, due to its lower melting point, it cannot operate at a higher temperature compared to other materials. Also, during the simulation, we have considered there were no liquid leakages. This paper would present insight into the operation of various phase change materials during the discharge of a battery. Furthermore, variation in thermal properties of materials can be explored based on simulations. This research can be further extended to solar, space, food, pharmaceutical, and various other industries where stable operating temperatures are required [18-20]. As PCM have high heat storage capabilities compared to sensible materials, it could be helpful for usage in food industry during distribution which requires low temperatures. Also, PCM can operate in wide temperature range, whose potential is being used in concentrated solar power plants as heat transfer fluid for producing electricity.

\section{Mathematical modeling}

\subsection{Battery model}

Initially, a Li-ion cell having a nominal capacity of $6.5 \mathrm{~A}-\mathrm{h}$ with a height of $75 \mathrm{~mm}$, length $100 \mathrm{~mm}$, and a width of $2.5 \mathrm{~mm}$ was designed in SOLID WORKS.

This battery geometry consists of 3 cells connected in series with a positive and negative tab on each cell, in turn, these cells are connected with a busbar element as shown in Figure 2. The model of battery was built in ANSYS fluent 2020 software. A multi-scale multi-dimensional model (MSMD) based on Newman, Tiedemann, Gu and Kim NTGK (E-chem model) method was selected with a maximum voltage of a cell is $4.2 \mathrm{~V}$ and a min voltage of $2.8 \mathrm{~V}$ to simulate the working of a battery. The following governing equations below are involved in solving this model [21].

The CFD model uses energy equation mentioned in equation (1) to solve temperature field involved in simulation:

$$
\frac{\partial\left(\rho * h_{e}\right)}{\partial t}+\nabla *\left(V * \rho * h_{e}\right)=\nabla *(k * \nabla T)+S_{h},
$$

here $\rho$ is the density, $T$ is the temperature, $k$ is the thermal conductivity, $h_{e}$ and $S_{h}$ are sensible enthalpy and volumetric source term respectively.

Firstly, the rate of volumetric current transfer related to the negative or positive phase potential is written in the mathematical equation (2).

$$
J_{\text {ech }}=a * Y *[U-(\Phi+-\Phi-)]
$$

where $a$ denotes the specified area of an electrode; $U, Y$ the model parameters which are a function of depth of discharge determined by (NTGK) model; $\Phi+$ and $\Phi-$ are positive and negative phase potentials respectively; $J_{\mathrm{ech}}$ is the volumetric current transfer rate.

Equation (3) represents the depth of discharge (DOD)

$$
D O D=\left(v o l / 3600 * Q_{a h}\right) * \int j * d t
$$



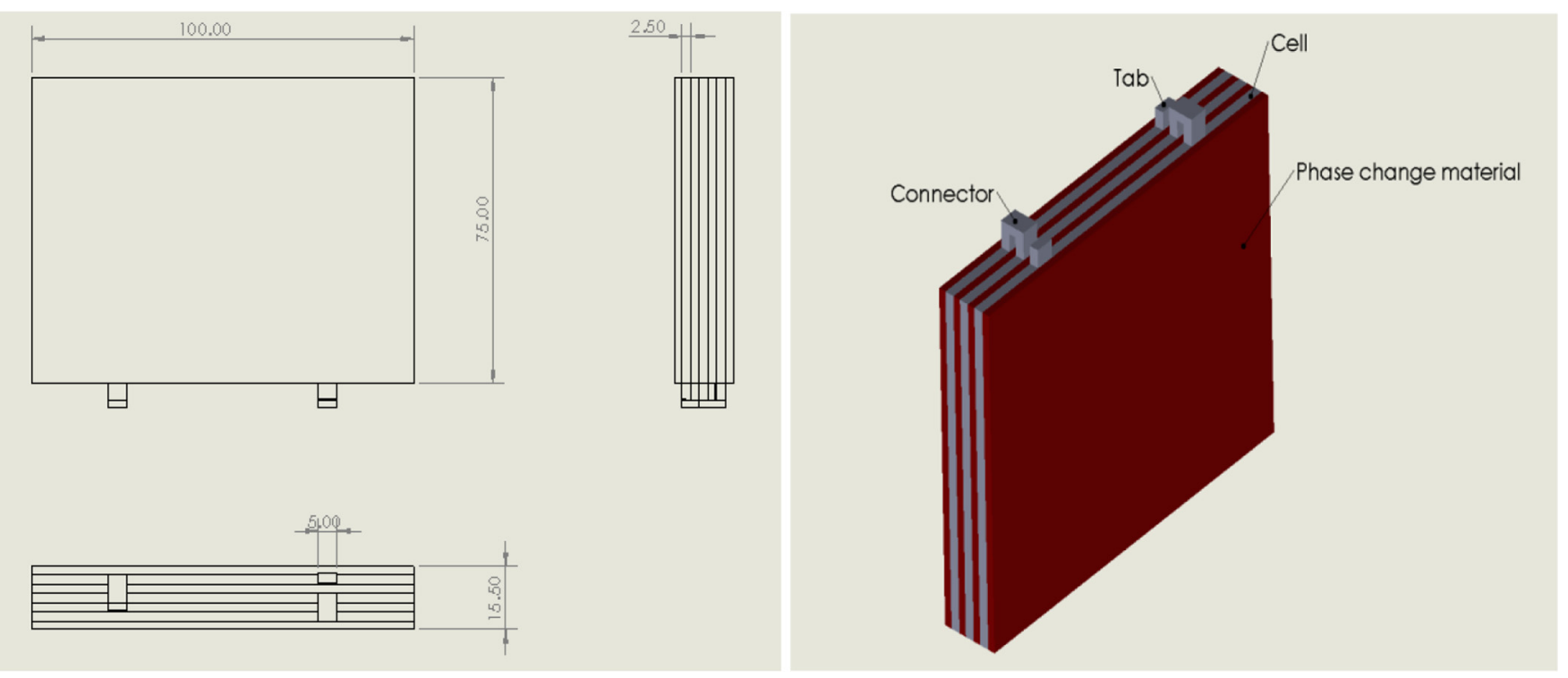

Fig. 2. Battery model specifications with PCM included.

where Vol denotes the battery volume, and $Q_{\mathrm{Ah}}$ is the total capacity $(\mathrm{Ah})$ of the battery. ANSYS utilizes the following set of formulas for determining the $Y$ and $U$ functions.

$$
Y=\left(\sum a_{n}\left(D O D^{n}\right) \exp \left[-C_{1} *\left(1 / T-1 / T_{r e f}\right)\right]\right)
$$

where, $n=0,1,2,3,4$

$$
\begin{aligned}
U & =\left(\sum b_{n}\left(D O D^{n}\right)\right)-C_{2} *\left[T_{r t}-T_{r e f}\right] \quad \text { where, } n \\
& =0,1,2,3
\end{aligned}
$$

where $C_{1}$ and $C_{2}$ are the battery-specific NTGK model constants, $T_{\mathrm{rt}}$ is the real-time temperature, $T_{\text {ref }}$ is the reference temperature. The electrochemical reaction heat is calculated as in following equation (6)

$$
Q_{e c h}=J_{e c h} *[U-(\Phi+-\Phi-)-T * d u / d t]
$$

where the foremost term in refers to heat due to potential difference and the secondary term refers to the entropic heat.

\subsection{PCM model}

The solidification/melting model was used in ANSYS fluent for the phase change process to occur in the setup. Enthalpy formulation is an important concept used for solving the phase change problem with the below provided equations for enthalpy formulation [22]. For a phasechange process involving either melting or freezing, the following energy conversation equation (7) is used:

$$
\frac{\partial H}{\partial t}=\nabla(\lambda k(\nabla T))
$$

where the total volumetric heat enthalpy is $H$, in $\mathrm{J} / \mathrm{m}^{3}, t$ is the time in seconds(s); $\lambda_{k}$ is the thermal conductivity material used as a PCM and $T$ is the temperature. Equation (8) represents the total volumetric enthalpy

$$
H(t)=h(t)+\rho * f(t) * L
$$

where sensible volumetric enthalpy is $h$, in $\mathrm{J} / \mathrm{m}^{3}, \rho$ is the density of PCM in liquid phase, in $\mathrm{kg} / \mathrm{m}^{3} ; f$ is the melt fraction; and latent heat of fusion $\mathrm{L}$, in $\mathrm{J} / \mathrm{kg}$. The expression (9) represents sensible volumetric enthalpy.

$$
h=\int \rho * c p * d T,
$$

where the integral ranges from Tm-T; where $\rho$ is the density at material phase in $\mathrm{PCM}$, in $\mathrm{kg} / \mathrm{m}^{3} ; C_{p}$ is the specific heat at material phase, $T$ is the temperature, in ${ }^{\circ} \mathrm{C}$; and $t_{m}$ is the melting temperature, in ${ }^{\circ} \mathrm{C}$. The following equations (10)-(12) represent the enthalpy of PCM at various temperature zones, where the integral ranges from $\mathrm{Tm}-\mathrm{T}$.

$$
\begin{gathered}
H=\int \rho_{s} * C_{p, s} * d T, \quad T<T_{m}(\text { solid }) \\
H=\rho_{l} * f * L, \quad T=T_{m}(\text { melting }) \\
H=\int \rho_{l} * C_{p, l} * d T+\rho_{l} * L, \quad T>T_{m} \text { (liquid). }
\end{gathered}
$$

The phase change of liquid fraction is given as (13) where,

$$
\begin{aligned}
& f=0, \text { if } T<T_{m}(\text { solid }) \\
& f=0-1, \text { if } T=T_{m}(\text { melting }) . \\
& f=0, \text { if } T>T_{m}(\text { liquid })
\end{aligned}
$$


Table 1. Mesh-independence study for simulation of battery.

\begin{tabular}{llll}
\hline Properties & Mesh-1 & Mesh-2 & Mesh-3 \\
\hline No of elements & 1555 & 157245 & 4345320 \\
Max. Surface temperature of cell $(\mathrm{K})$ & 302.0078 & 302.087 & 302.088 \\
\hline
\end{tabular}

Table 2. Material properties of cell, Tab and connecting bar.

\begin{tabular}{llll}
\hline Properties & Material of cell & Material of Tab & Material of connecting bar \\
\hline Density $\left(\mathrm{kg} / \mathrm{m}^{3}\right)$ & 2092 & 8978 & 8978 \\
Specific heat $(\mathrm{J} / \mathrm{kg} \cdot \mathrm{K})$ & 678 & 381 & 381 \\
Thermal conductivity $(\mathrm{W} / \mathrm{m} \cdot \mathrm{K})$ & 18.4 & 387.6 & 387.6 \\
\hline
\end{tabular}

\section{Solution methodology}

Finite volume method (FVM) is used to solve equations while conducting simulations in ANSYS Fluent. All simulations were conducted in laminar flow and transient-state as the grashoff $(\mathrm{Gr})$ is within the limits and battery discharges with respect to time. The model was meshed in ANSYS meshing with 227010 nodes and 157245 elements. Based on the mesh independence study in Table 1 we have selected the respective nodes and elements to reduce the computational time as the values seem to not change much with increased element size.

ANSYS [23], we have considered three models for running the simulation, as temperature difference is involved energy equation is included, also we are dealing with a phase change material so solidification/melting was incorporated, and MSMD battery model to simulate battery operation. The MSMD model uses NTGK method to simulate battery operation. Newman, Tiedemann, Gu and Kim (NTGK) model is one of the 3 sub-models used for solving physical and electrochemical events in a battery cell. Correspondingly, joule heat source and Echem heat source were turned on in MSMD model for thermal and electrical analysis. We have deliberated battery specification of 2010 Toyota Prius vehicle for our cells and NTGK model parameters $\mathrm{Y}$ and $\mathrm{U}$ are a function of depth of discharge determined by [24]. The following parameters given in Table 2 were adopted as lithium-ion for cell and copper for tab and connector as material properties and the required phase potentials for positive and negative tabs of the battery are considered as indicated [25]. Solidification/melting model was used to find the phase transition in terms of liquid fraction for PCM. This transition zone requires a larger amount of latent heat to be absorbed or ejected as phase change occurs.

As stated, we have considered four-phase change materials, n-octadecane, N-eicosane, methyl-palmitate, and OM-35, these materials were wrapped in a container around the cell packed with phase change material. PCM's have different operating conditions and it requires evaluating the suitable PCM for the environment based on various experiments and simulations because various weather conditions demand different thermal properties for better operation of material. Hence, it is necessary to select PCM which could adapt to any weather conditions maintaining optimum efficiency. We have selected these materials considering various ambient conditions around the world, which would suit the melting temperature of PCM. Because a material with $25^{\circ} \mathrm{C}$ as melting temperature showcases low performance in areas where ambient temperatures range between $30^{\circ} \mathrm{C}$ and $32^{\circ} \mathrm{C}$ on normal days. As discussed earlier, latent heat is required for phase transition and a larger value would indicate a better temperature control because of its capacity to hold more amount of heat. The following material parameters listed in Table 2 were used for respective materials. According to the battery conditions we have considered it is necessary to set up maximum and minimum voltage conditions during operations to avoid system failure. Since many appliances have rated voltage capacity to operate, situations, where a voltage being supplied is higher or lower than required, might damage the entire circuit. Keeping in mind these practical conditions we have mentioned the max. and min. voltage values for each cell during the simulation. Furthermore, battery simulation was carried out considering negligible short-circuit potential. Since each PCM has a varying thermal property, the ambient temperature was varied accordingly. Moreover, to find if PCM has a significant effect on temperature change in battery, a model without PCM was considered to be operating under natural convection without any cooling system. Figure 3 indicates the discharge potential of the battery with respect to time at changing C-rates. These C-rates provide dictate the amount current to be supplied throughout the system. Here each cell with a maximum voltage and minimum voltage of $4.1 \mathrm{~V}$ and $2 \mathrm{~V}$ respectively was indicated in ANSYS. The reason for considering 3 cells over 2 cells in the simulation is to evaluate the performance for the PCM in an extreme condition. Because in a battery with 3-cells the center cell is in contact with PCM experiencing heat on both the sides, whereas in a 2-cell they are in contact with PCM which do 'not undergo such heat supply on both their sides. The method used for modeling also a key issue to be noted, we have used a SIMPLE pressure-velocity scheme with second-order upwind method to solve pressure, 


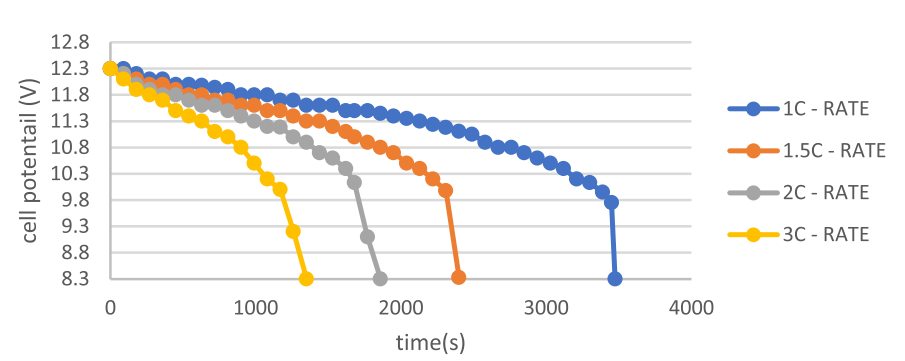

Fig. 3. Variation in cell potential as battery discharges at various C-rate.

momentum, and energy equations. Second-order implicit method for the transient formulation was adopted in ANSYS FLUENT. Compared to the first-order implicit method, second-order implicit method provides much accurate solutions.

\section{Results}

These simulation results endowed would describe the impact of using PCM with the designed battery, helpful in determining the thermal performance. The results present that surface temperature on cell increases with varying discharge rate. Where a $1 \mathrm{C}$-rate condition produces $3.6 \mathrm{~A}$ of current to flow in a battery, as the C-rate increases the flow of current increases proportionally causing the battery to discharge at a faster rate as seen in Figure 3. Furthermore, based on the temperature contour results obtained, the surface temperature of the cell was highest near the tabs and decreases as we move away.

Beginning with, Methyl-palmitate which is a nonparaffin material, with $297 \mathrm{~K}$ and $300 \mathrm{~K}$ as its solidification and melting temperatures respectively. Table 3 provides the list of thermo physical properties for methyl-palmitate.

List of thermo physical properties for methylpalmitate. The graphs plotted in Figure 4 illustrate a better understanding of the temperature variations of the cooled battery module as it exhibits a better temperature control in comparison to the battery without PCM. Here a Peak temperature of $298.9 \mathrm{~K}$ and $317.95 \mathrm{~K}$ was noted at 3C-rate for battery with and without $\mathrm{PCM}$ respectively. Overall, the difference in temperature change is listed in Table 5. Though it has a better temperature control its comparatively lower melting point wouldn't be able to handle higher temperature conditions as other materials do, which can be depicted through its liquid fraction.

$\mathrm{N}$-octadecane is a paraffin material Contours of liquid fraction and static temperature at 3C-Rate were shown in Figure 7. From these, it can be depicted that the surface temperature of cell is higher near the cell tab's and the liquid fraction was also higher for PCM attached to the adjacent faces of cell whose corresponding value is 0.406 . While, the peak temperature obtained was $302.2 \mathrm{~K}$. The graphs plotted in Figure 6 exhibit a similar trend as showcased for previous material and seems to control battery temperature in an efficient way. This material has its melting temperature in range suitable for cooler weather conditions. So, the peak temperature of battery

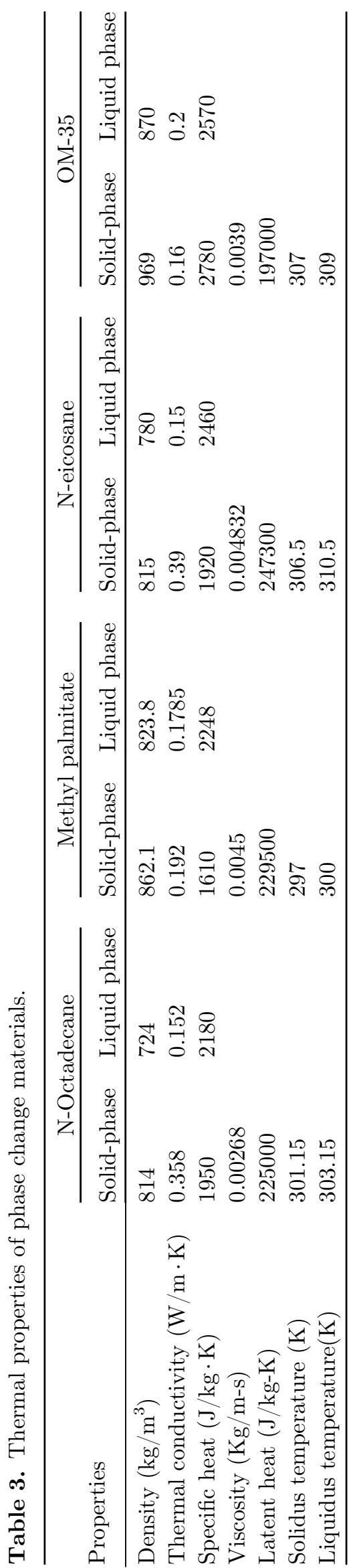



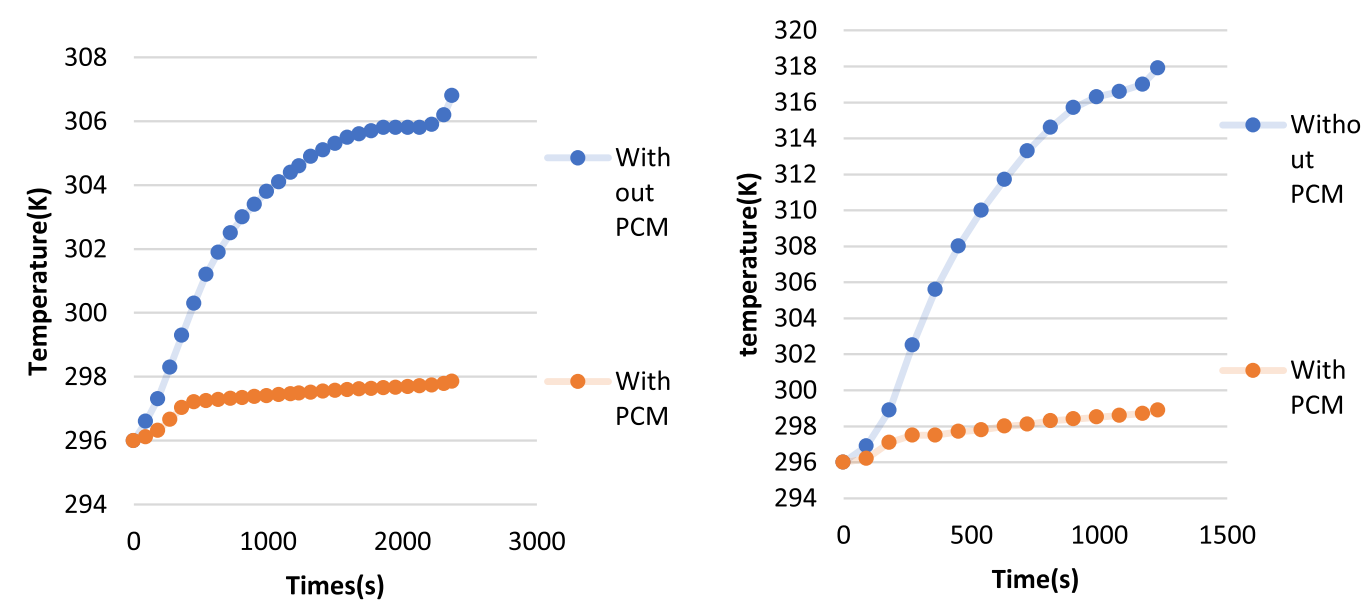

Fig. 4. Variation of temperature with time for cell with and without PCM (Methyl-palmitate) at 1.5C-Rate (left) and 3C-Rate (right).

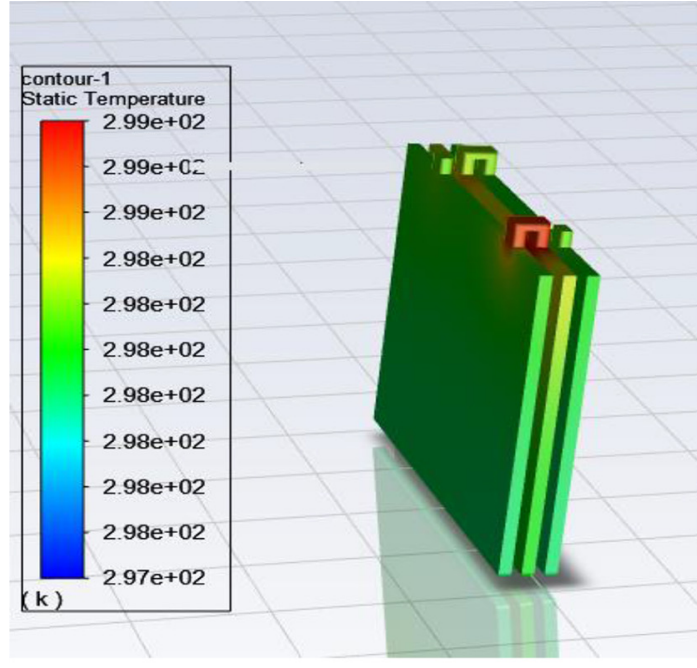

(a)

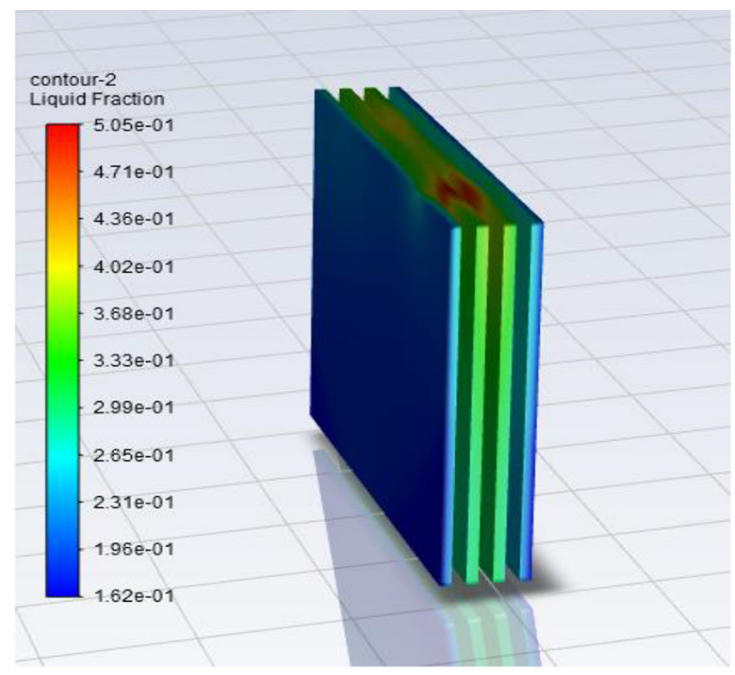

(b)

Fig. 5. Contours of Methyl-palmitate (a) static temperature (b) liquid fraction at 3c-rate.

involving octadecane as phase change material during operation is $302.2 \mathrm{~K}$, which is comparatively higher to methyl palmitate, but though N-octadecane has a higher melting point its liquid fraction values are greater compared to methyl palmitate because of its lower latent heat.

$\mathrm{N}$-eicosane is a paraffin material belonging to alkane group with a longer carbon chain (C20). From all the materials chosen it has a higher latent heat. As per the contours shown in Figure 9 eicosane has the least proportion of liquid fraction and higher surface temperatures compared to other materials. There is a temperature difference of $18 \mathrm{~K}$ between the cell cooled with and without a phase change material. As per the indications in Figure 8, though it operated at higher temperatures N-eicosane has controlled the temperature of battery in an effective way compared to other materials. As eicosane has a higher latent heat of fusion compared to other material, it might be a reason for its efficient operation. Since, eicosane has a melting temperature of $35^{\circ} \mathrm{C}$ it can operate in harsher environment conditions. In comparison, better liquid fraction values in Table 4 are noted for eicosane indicating it can further operate at higher discharge rates or higher battery capacities.

OM-35 is a phase change material manufactured by PLUSS polymers, it contains various salts and nucleating additives to balance the solid and liquid phases to be attained during melting. It has higher operating temperature compared to all other materials considered. Though OM-35 has melting temperature almost equal to N-eicosane, when noticed from Table 5 there is lesser temperature control in comparison. Which provides us 

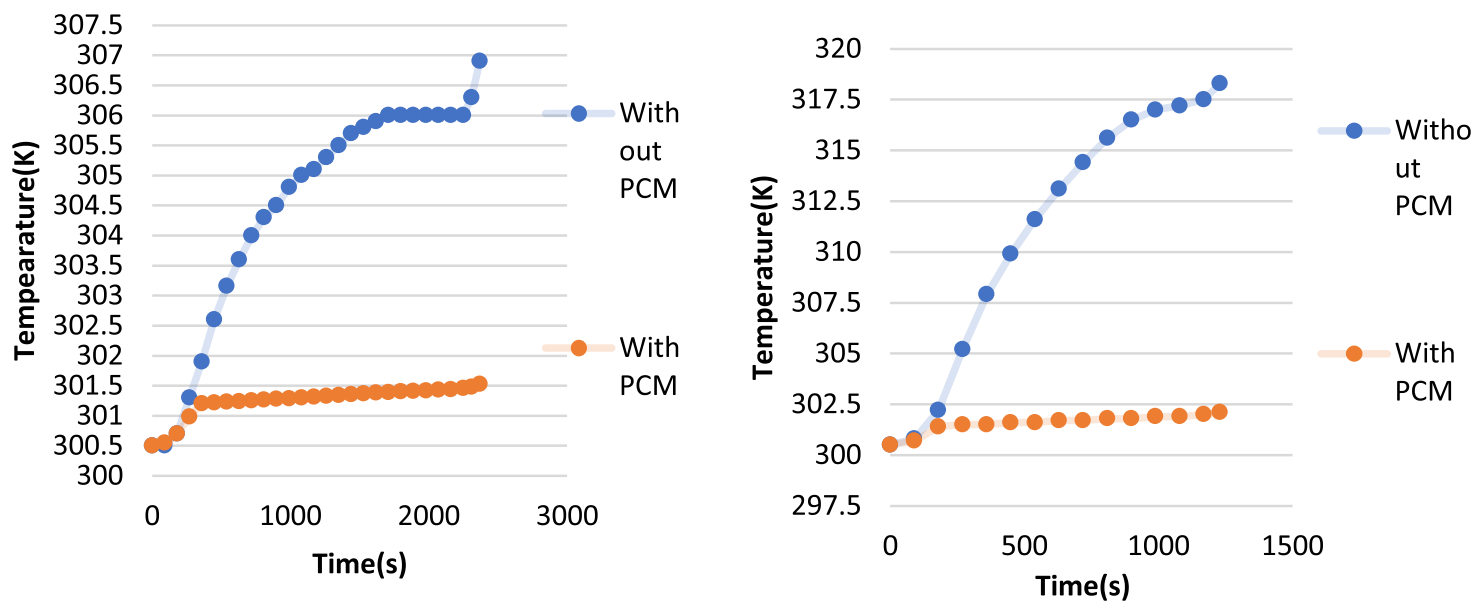

Fig. 6. Variation of temperature with time for cell with and without PCM (Octadecane) at 1.5C-Rate (left) and 3C-Rate (right).

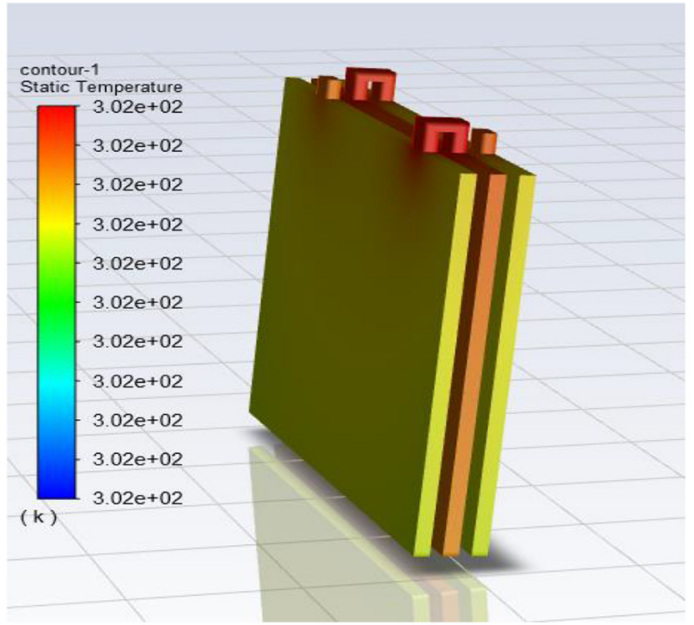

(a)

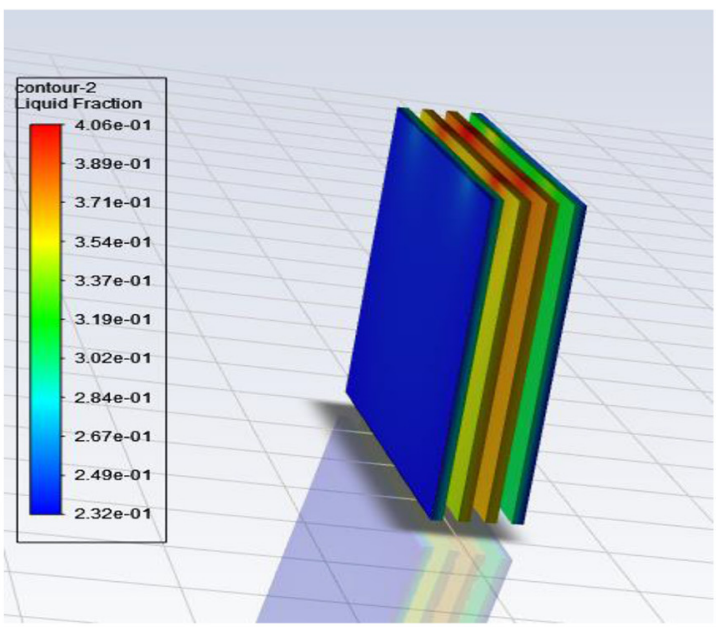

(b)

Fig. 7. Contours of Octadecane (a) static temperature (b) liquid fraction at 3C-rate.
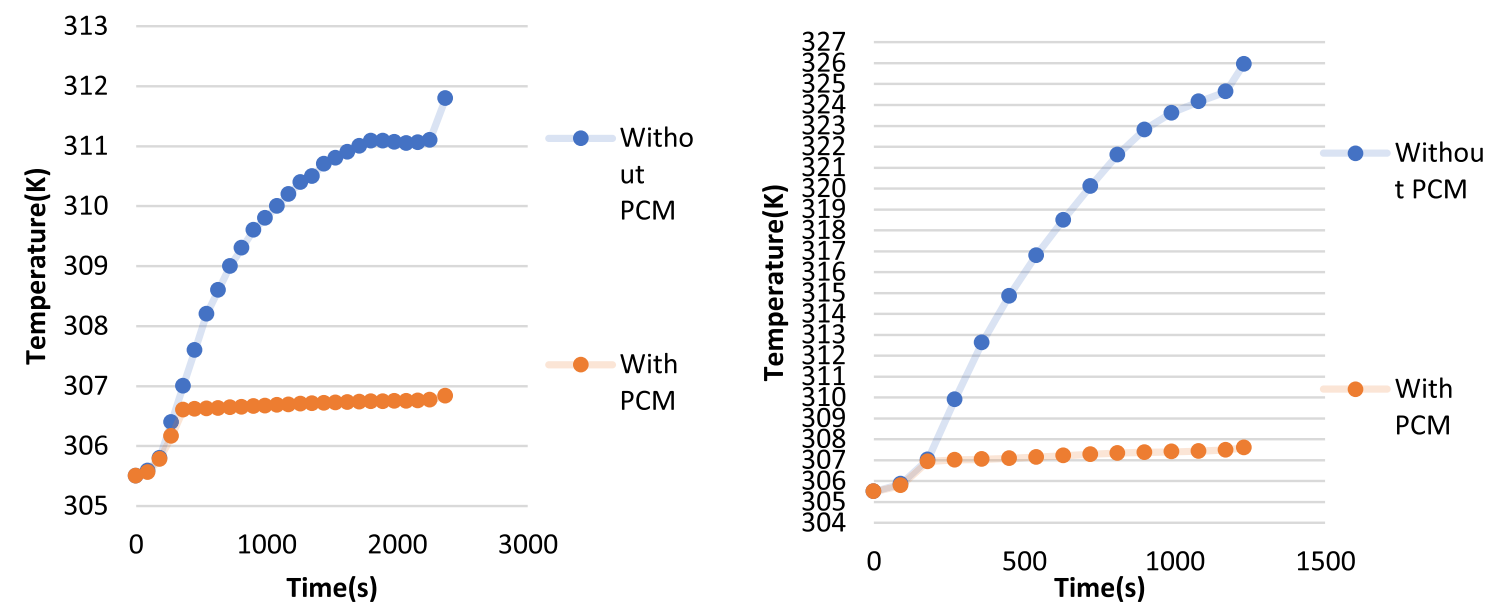

Fig. 8. Variation of temperature with time for cell with and without PCM (Eicosane) at 1.5C-Rate (left) and 3C-Rate (right). 
Table 4. Liquid fraction values of phase change materials at different C-rates.

\begin{tabular}{lllll}
\hline \multirow{2}{*}{ Material } & \multicolumn{4}{c}{ Liquid fraction } \\
\cline { 2 - 5 } & 1C-RATE & 1.5C-RATE & 2C-RATE & 3C-RATE \\
\hline N-octadecane & 0.0874 & 0.153 & 0.215 & 0.406 \\
Methyl palmitate & 0.139 & 0.239 & 0.315 & 0.505 \\
N-eicosane & 0.0245 & 0.0524 & 0.0835 & 0.164 \\
OM-35 & 0.09 & 0.201 & 0.301 & 0.469 \\
\hline
\end{tabular}

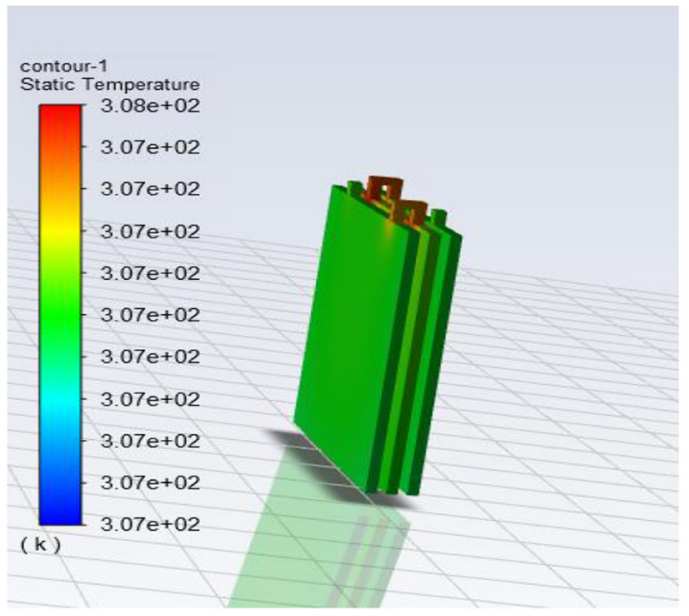

(a)

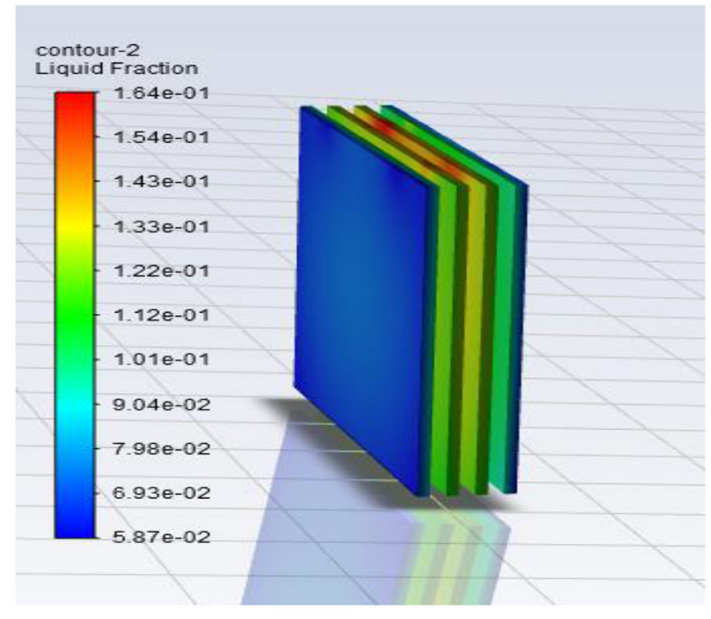

(b)

Fig. 9. Contours of N-eicosane (a) static temperature (b) liquid fraction at 3C-rate.

that variation in latent heat and thermal conductivity effects the performance of a material. From these simulations the maximum temperature of battery using OM-35 has a peak temperature of $308.57 \mathrm{~K}$ at $3 \mathrm{C}$ rate. Whereas, the liquid fraction values were higher for PCM walls in contact to cells on either face. Figure 10 provides the variation in temperature profile at various C-rates. The results obtained from simulations based on temperature variation were tabulated in Table 5 provides us with a better overall view on the performance of each PCM material in limiting surface temperature of cell. The temperature difference trend observed at $1 \mathrm{C}$-rate for all materials showcases that methyl palmitate has better temperature control followed by $\mathrm{N}$-octadecane, N-eicosane and OM-35. A similar trend was observed for $1.5 \mathrm{C}$ and $2 \mathrm{C}$ rate. However, a shift in temperature difference was noted at $3 \mathrm{C}$-rate where Methyl palmitate was followed by N-eicosane, OM-35 and N-octadecane.

\section{Conclusion}

At present, battery vehicles are considered to be an alternative to IC engines as they can help tackle the emissions in a better way [26]. Lithium-ion batteries are majorly used to power battery vehicle in the current century due to their better energy density and power to weight ratio [27]. So, battery thermal management system is crucial in its maintenance. Using phase change materials for BTMS would be a viable alternative to all traditional cooling systems in future days. Based on the results obtained from the simulation each material has a different field of advantage to perform efficiently, N-eicosane has better latent heat and thermal conductivity whereas Methyl palmitate has better temperature control comparatively. For instance, temperature difference was comparatively higher for methyl palmitate but its liquid fraction value was higher compared to others which might affect its performance if temperature increases further. In addition, N-eicosane which has slightly lesser temperature difference compared to OM-35 and other materials has displayed a lesser liquid fraction values due to its high latent heat allowing it to perform in further stressed conditions. Considering normal working conditions under which we have performed our simulations, phase change materials prove to be an efficient alternative for other cooling systems and N-eicosane has produced convincing results in terms of liquid fraction and temperature control, as the relative temperature between N-eicosane and methyl-palmitate is not too high making it a much efficient performer among its peers. While working under extreme stressed conditions further research on phase change materials should be conducted on how they perform. Moreover, enhancing a phase change material might also seem to provide an enhanced performance which needs to be explored. 

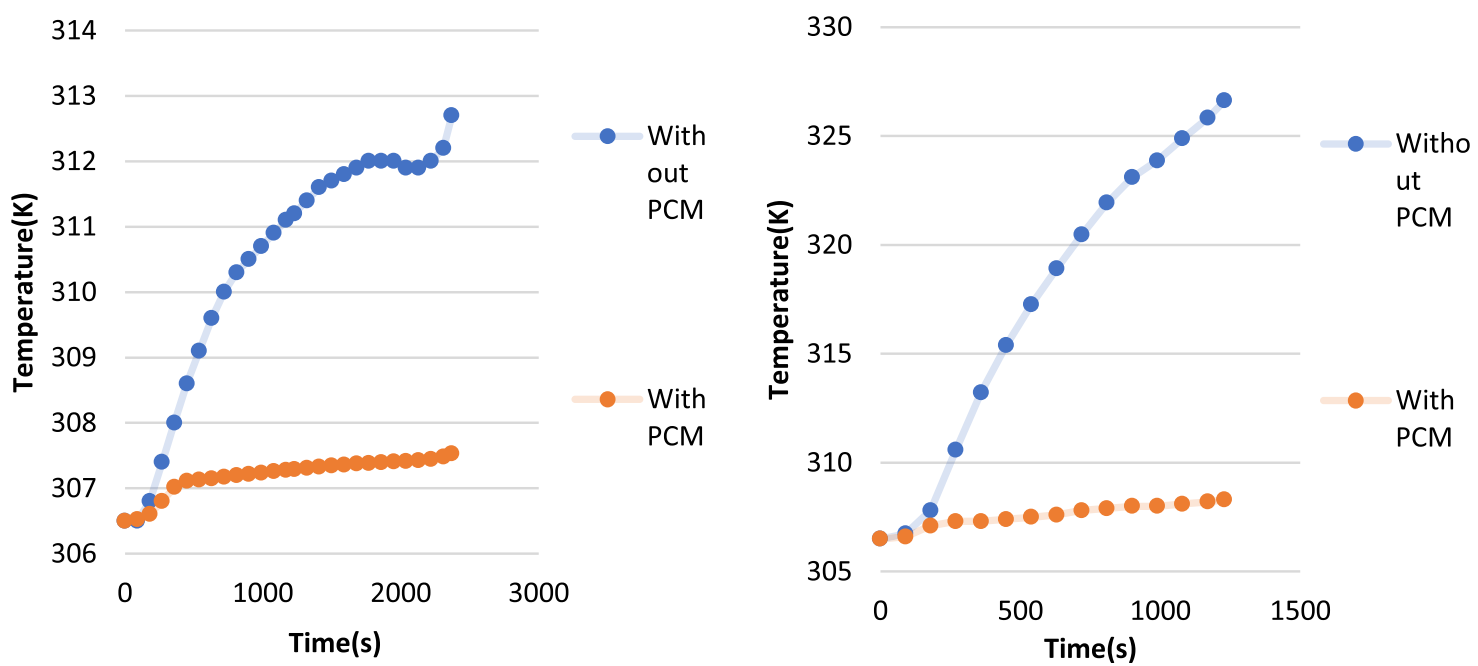

Fig. 10. Variation of temperature with time for cell with and without PCM (OM-35) at 1.5C-Rate (left) and 3C-Rate (right).

Table 5. Temperature difference at cell surface for various operating conditions.

\begin{tabular}{|c|c|c|c|c|c|c|c|c|c|c|c|c|}
\hline \multirow{2}{*}{ Material } & \multicolumn{4}{|c|}{$\begin{array}{l}\text { Peak temperature }(\mathrm{K}) \\
\text { (Without PCM) }\end{array}$} & \multicolumn{4}{|c|}{$\begin{array}{c}\text { Peak temperature (K) } \\
\text { (With PCM) }\end{array}$} & \multicolumn{4}{|c|}{ Temperature difference $(\mathrm{K})$} \\
\hline & $1 \mathrm{C}$ & $1.5 \mathrm{C}$ & $2 \mathrm{C}$ & $3 \mathrm{C}$ & $1 \mathrm{C}$ & $1.5 \mathrm{C}$ & $2 \mathrm{C}$ & $3 \mathrm{C}$ & $1 \mathrm{C}$ & $1.5 \mathrm{C}$ & $2 \mathrm{C}$ & $3 \mathrm{C}$ \\
\hline & 303.28 & 306.93 & 310.2 & 318 & 01.35 & 301.52 & 301.65 & 302.14 & 1.93 & 5.4 & 8.5 & 16.2 \\
\hline Methyl palmitate & 302.91 & 306.82 & 309.98 & 317.96 & 297.47 & 297.85 & 298.12 & 298.94 & 5.44 & 8.97 & 11.86 & 19.02 \\
\hline N-eicosane & 308.51 & 311.87 & 314.93 & 325.96 & 306.63 & 306.83 & 306.91 & 307.59 & 1.88 & 5.04 & 8.02 & 18.37 \\
\hline OM-35 & 308.65 & 312.5 & 315.95 & 326.62 & 307.23 & 307.53 & 307.89 & 308.57 & 1.42 & 4.97 & 7.96 & 18.05 \\
\hline
\end{tabular}

\section{References}

1. J. Kim, J. Oh, H. Lee, Review on battery thermal management system for electric vehicles, Appl. Therm. Eng. 149, 192-212 (2019)

2. T. Talluri, T. Hyeong Kim, K.J. Shin, Analysis of a battery pack with a phase change material for the extreme temperature conditions of an electrical vehicle, Energies 13, 507 (2020)

3. Z. Ahmad Qureshi, H. Muhammad Ali, S. Khushnood, Recent advances on thermal conductivity enhancement of phase change materials for energy storage system: a review, Int. J. Heat Mass Transfer 127, 838-856 (2018)

4. A. Mills, M. Farid, J.R. Selman, S. Al-Hallaj, Thermal conductivity enhancement of phase change materials using a graphite matrix, Appl. Thermal Eng. 26, 1652-1661 (2006)

5. N.I. Ibrahim, F.A. Al-Sulaimana, S. Rahmana, B.S. Yilbasb, A.Z. Sahinb, Heat transfer enhancement of phase change materials for thermal energy storage applications: a critical review, Renew. Sustain. Energy Rev. 74, 26-50 (2017)

6. H. Fathabadi, High thermal performance lithium-ion battery pack including hybrid active-passive thermal management system for using in hybrid/electric vehicles, Energy $\mathbf{7 0}$, 529-538 (2014)
7. Z. Ling, J. Chen, X. Fang, Z. Zhang, T. Xu, X. Gao, S. Wang, Experimental and numerical investigation of the application of phase change materials in a simulative power batteries thermal management system, Appl. Energy 121, 104-113 (2014)

8. Y. Zhao, B. Zou, C. Li, Y. Ding, Active cooling based battery thermal management using composite phase change materials, Energy Proc. 158, 4933-4940 (2019)

9. A. Sharma, V.V. Tyagi, C.R. Chen, D. Buddhi, Review on thermal energy storage with phase change materials and applications, Renew. Sustain. Energy Rev. 13, 318-345 (2009)

10. Z. Rao, S. Wang, G. Zhang, Simulation and experiment of thermal energy management with phase change material for ageing LiFePO4 power battery, Energy Convers. Manag. 52, 3408-3414 (2011)

11. R. Huang, Z. Li, W. Hong, Q. Wu, X. Yu, Experimental and numerical study of PCM thermophysical parameters on lithium-ion battery thermal management, Energy Rep. 6, 8-19 (2020)

12. J. Zhang, X. Li, G. Zhang, Y. Wang, J. Guo, Y. Wang, Q. Huang, C. Xiao, Z. Zhong, Characterization and experimental investigation of aluminum nitride-based composite phase change materials for battery thermal management, Energy Convers. Manag. 204, 112319 (2020)

13. R. Pradeep, V. Thangavel, Investigations on melting and solidification of a battery cooling system using different phase change materials, Thermal Sci. 25, 220-220 (2020) 
14. R.M. Saeeda, J.P. Schlegela, C. Castanoa, R. Sawaftab, V. Kuturub, Preparation and thermal performance of methyl palmitate and lauric acid eutectic mixture as phase change material (PCM), J. Energy Storage 13, 418-424 (2017)

15. X. Zhang, C. Zhu, G. Fang, Preparation and thermal properties of n-eicosane/nano- $\mathrm{SiO}_{2} /$ expanded graphite composite phase-change material for thermal energy storage, Mater. Chem. Phys. 240, 122178 (2020)

16. R. Saxena, D. Rakshit, S.C. Kaushik, Experimental assessment of characterised PCMs for thermal management of buildings in tropical composite, Climate DOI: 10.11159/htff18.170

17. N. Javani, I. Dincer, G.F. Naterer, B.S. Yilbas, Heat transfer and thermal management with PCMs in a Li-ion battery cell for electric vehicles, Int. J. Heat Mass Transfer 72, 690-703 (2014)

18. M. Mofijur, T. Meurah Indra Mahlia, A. Susan Silitonga, H. Chyuan Ong, M. Silakhori, M. Heikal Hasan, N. Putra, S.M. Ashrafur Rahman, Phase Change Materials (PCM) for solar energy usages and storage: an overview, Energies 12, 3167 (2019)

19. E. Alehosseini, S.M. Jafari, Micro/nano-encapsulated phase change materials (PCMs) as emerging materials for the food industry, Trends Food Sci. Technol. 91, 116-128 (2019)

20. T.Y. Kim, B.-S. Hyun, J.-J. Lee, J. Rhee, Numerical study of the spacecraft thermal control hardware combining solid-liquid phase change material and a heat pipe, Aerospace Sci. Technol. 27, 10-16 (2013)

21. S.S. Madani, M.J. Swierczynski, S.K. Kaer, The discharge behavior of lithium-ion batteries using the Dual-Potential Multi-Scale Multi-Dimensional (MSMD) Battery Model, in 2017 12th Int. Conf. Ecol. Veh. Renew. Energies, EVER, 2017. DOI: 10.1109/EVER.2017.7935915

22. I. Sarbu, C. Sebarchievici, Chapter 4-Thermal Energy Storage, Solar Heating and Cooling Systems Fundamentals, Experiments and Applications, 2017, 99-138

23. ANSYS Inc., ANSYS Fluent Theory Guide (Release 2020 R2) (ANSYS Inc.: Canonsburg, PA, USA, 2017)

24. U. Seong Kim, J. Yi, C. Burm Shin, T. Han, S. Park, Modeling the dependence of the discharge behavior of a lithium-ion battery on the environmental temperature, J. Electrochem. Soc. 158, A611-A618 (2011)

25. Y. Liu, Y. Gene Liao, M.-C. Lai, Transient temperature distributions on lithium-ion polymer SLI battery, Vehicles 1, 127-1937 (2019)

26. E. Helmers, P. Marx, Electric cars: technical characteristics and environmental impacts, Helmers and Marx Environmental Sciences Europe 24, 14 (2012)

27. C. Iclodean, B. Varga, N. Burnete, D. Cimerdean, B. Jurchis, Comparison of different battery types for electric vehicles, IOP Conf. Series: Mater. Sci. Eng. 252, 012058 (2017)

Cite this article as: Pusapati Laxmi Narasimha Raju, Chalumuru Manas, Harish Rajan, Computational modeling of battery thermal energy management system using phase change materials, Int. J. Simul. Multidisci. Des. Optim. 13, 1 (2022) 